\title{
Análises contrastivas de microestruturas em dicionários escolares
}

\author{
Márcio Sales Santiago \\ UFRGS
}

\begin{abstract}
Resumo
Este artigo resulta de uma breve observação realizada em dois dicionários escolares brasileiros: o Aurélio Júnior: dicionário escolar da língua portuguesa e o Minidicionário da língua portuguesa Ruth Rocha. O principal objetivo deste estudo é analisar contrastivamente algumas microestruturas contidas nas referidas obras à luz dos princípios da Lexicografia Pedagógica, com a finalidade de tecer observações analíticas acerca das informações e características presentes em cada um dos verbetes.
\end{abstract}

Palavras-chave: Dicionário escolar. Lexicografia Pedagógica. Metalexicografia. Microestrutura.

\begin{abstract}
This article presents a preliminary study of two Brazilian school dictionaries: the Aurélio Júnior: dicionário escolar da língua portuguesa and the Minidicionário da lingua portuguesa Ruth Rocha. The main objective of this study is to analyze some microstructures in these dictionaries through a contrastive analysis following the principles of Pedagogical Lexicography. The paper discusses the analysis of the information and the features that are in the entries.
\end{abstract}

Keywords: Pedagogical Lexicography. School Dictionary. Metalexicography. Microstructure.

\section{INTRODUÇÃO}

Teoricamente, a Lexicografia é definida como sendo a ciência responsável por estudar aspectos relativos ao modo como se organizam e se elaboram os dicionários. No plano aplicado, a Lexicografia é, segundo a concepção clássica, a arte e a técnica de elaborar dicionários. O termo lexicografia pode se referir ainda ao conjunto dos dicionários de um determinado idioma: a lexicografia portuguesa, a lexicografia inglesa, a lexicografia espanhola, etc.

Em razão dos avanços nos estudos que emanam dessa temática, surgem nos dias de hoje, principalmente nas universidades, inúmeros trabalhos que demonstram análises quanto à 
estrutura, à disposição e à utilidade dos dicionários. Tais pesquisas revelam, entre outros resultados, que alguns dicionaristas e/ou autores de dicionários propõem obras que desprezam as orientações e as formatações estabelecidas pela ciência lexicográfica, motivo pelo qual Krieger (2003: 71) observa que "entre os principais fatores, pode-se dizer que a lexicografia, quer teórica quer aplicada, é muito pouco estudada em nosso meio".

Assim, no intuito de tentar contribuir com estudos teóricos de Lexicografia, objetivamos, neste artigo, realizar breves análises contrativas acerca de aspectos relativos à microestrutura dos dicionários Aurélio Júnior: dicionário escolar da língua portuguesa (Ferreira, 2005) e Minidicionário da língua portuguesa Ruth Rocha (Rocha, 2005), ambos com uma média de 30.000 verbetes. Desse grande universo lexical, extraímos alguns verbetes que servem como amostra para a análise, os quais foram integramente transcritos das referidas obras lexicográficas para, em seguida, serem estudados e avaliados. Convém ressaltar que este trabalho tem por base os pressupostos teóricos da Lexicografia Pedagógica ${ }^{1}$, vertente da Lexicografia responsável pelo estudo e avaliação do complexo processo organizacional do dicionário escolar.

\section{SOBRE O DICIONÁRIO: DEFINIÇÃO, TIPOS E ESTRUTURA}

O dicionário é uma obra metalinguística que se destina à consulta, pois é o lugar de registro e legitimação das unidades que compõem o léxico. Os estudos lexicográficos o classificam ainda como uma obra mais comumente organizada em ordem alfabética, por razões estruturais e de consulta, que retrata além de informações gramaticais, semânticas e pragmáticas, conhecimentos culturais referentes à língua em que ele está inserido através das unidades lexicais que o compõem.

Quanto aos tipos, apontamos como os modelos mais usuais na sociedade contemporânea os dicionários gerais de língua, também chamados de dicionários-padrão, os quais podem ser, em sua maioria, monolíngues, bilíngues ou trilingues. Além destes, existem também os modelos reduzidos, muito conhecidos pelo público em geral. São exemplos os minidicionários e dicionários de bolso. Outro tipo de dicionário encurtado, porém mais voltado para o ensino e aprendizagem de línguas, é o dicionário escolar, que, dependendo da finalidade e do tipo de usuário, pode ser monolíngue, bilíngue ou semibilingue. Engrossam ainda esta lista outros tipos,

\footnotetext{
${ }^{1}$ Também chamada de Lexicografia Didática.
} 
tais como: dicionários infantis, ilustrados, temáticos, técnico-científicos e dicionários eletrônicos, que podem ser utilizados com mídias específicas, geralmente através de CD-ROM, e dicionários on-line, os quais são acessados por meio da internet, além de outros. Vale salientar que, para categorizar esta variada tipologia de dicionário, três critérios fundamentais são levados em conta: o total de palavras-entrada, a finalidade e o público consulente para o qual se destina.

Em meio a esta diversificada categorização, percebemos que de todas as tipologias de dicionário existentes, o mais procurado pelo usuário é o minidicionário. Apontamos duas, entre algumas, como as principais razões dessa procura: o custo financeiro, ou seja, é um dicionário mais barato que o dicionário geral; é um dicionário fisicamente menor que o dicionário geral e, por conta disso, seu manuseio torna-se bem mais fácil.

No Brasil, existe uma grande busca por dicionários, os quais se destinam a um número impressionante de usuários, de níveis bastante diversificados. Segundo Krieger (2004/2005: 103), “os dicionários são produtos de alta vendagem e o público escolar é muito visado. De fato, há um crescimento editorial no plano da lexicografia pedagógica ou didática, que se destina aos estudantes no aprendizado de sua língua materna".

Como se percebe, o dicionário, além de ser um livro de consultas, é uma obra pedagógica e de representação cultural de uma determinada comunidade. No entanto, apesar de sua importância linguística e cultural, o dicionário é, sem dúvida, uma das obras que mais carece de uma melhor elaboração. Destaque-se que, até certo tempo, não havia critérios específicos para a elaboração dos dicionários utilizados na escola brasileira.

Pensando nisso, foi criada a Comissão Técnica de Avaliação de Livros Didáticos, pertencente ao Programa Nacional do Livro Didático $\left(\mathrm{PNLD}^{2}\right)$, do Ministério da Educação (MEC), composta uma equipe de profissionais especializados, com a missão de avaliar livros didáticos, entre os quais se incluem os dicionários produzidos e/ou reformulados no Brasil. Estes dicionários, se aprovados, são comprados pelo MEC para serem distribuídos nas escolas públicas de educação básica de todo o país. Ações dessa natureza são essenciais para que se saibam quais dicionários estão disponíveis para uso de uma comunidade linguística, uma vez que a norma apresentada neles é tida como uma imagem ideal. Tal atitude revela uma preocupação por parte do MEC com os repertórios elaborados e colocados à disposição no país.

2 “O PNLD consiste num processo complexo, desenvolvido em várias etapas, contando com a colaboração de técnicos do Ministério, professores universitários e linguistas” (Krieger, 2006: 236). 
Ressaltamos que a partir da triagem realizada pelo MEC, iniciada em 2004, os minidicionários foram adotados pelas escolas, já que não existia ou não se levava em conta a existência de um dicionário específico para ser usado em âmbito escolar. É importante observar que, até hoje, muitos professores não sabem a diferença entre ambos e, comumente, os dicionários escolares são chamados de minidicionários. Entretanto, graças ao esforço da comissão técnica de avaliação do PNLD na área de dicionários, este quadro, aos poucos, começa a mudar.

Em 2006, o PNLD representou importantes mudanças no tratamento e na seleção dos dicionários escolares, uma vez que reconheceu o papel pedagógico dessas obras. Foram adotadas novas diretrizes para aperfeiçoar o processo de seleção e aquisição de dicionários escolares. Além disso, foi proposta uma classificação dos repertórios em acervos, cada um deles destinado a uma etapa específica do processo de alfabetização e letramento dos alunos. Assim, os dicionários foram classificados como obras de tipo 1 , para o $1^{\circ}$ ano do ensino fundamental, com mínimo de 1.000 e máximo de 3.000 verbetes; de tipo 2 , do $2^{\circ}$ ao $5^{\circ}$ ano do ensino fundamental, entre 3.500 e máximo de 10.000 verbetes; e de tipo 3 , do $6^{\circ}$ ao $9^{\circ}$ ano do ensino fundamental, com mínimo de 19.000 e máximo de 35.000 verbetes.

É importante destacar que para o PNLD 2012 esta classificação que compatibiliza o dicionário à proposta lexicográfica do aluno passou por uma mudança, cujo resultado representou um rearranjo da proposta e a inclusão de um quarto grupo de dicionário, o de tipo 4, voltado para o ensino médio e profissionalizante, com mínimo de 40.000 e máximo de 100.000 verbetes. Avanços como este mostram, entre outros aspectos, que a necessidade de inclusão de uma outra tipologia na avaliação do Programa um incontestável reflexo do uso cada vez mais frequente do dicionário em todas as etapas de ensino da educação básica, como também no ensino profissionalizante.

Em relação à estrutura, o dicionário se organiza essencialmente em dois eixos: o da macroestrutura e o da microestrutura ${ }^{3}$. Na macroestrutura, o dicionário se organiza em três partes principais: as páginas iniciais da obra, o corpo do dicionário e as páginas finais do dicionário. As páginas iniciais frequentemente incluem apresentação, prólogo, introdução, instruções de uso do dicionário, listas e abreviaturas. Já o corpo do dicionário é constituído pela nomenclatura em si, isto é, o dicionário propriamente dito. É dentro da macroestrutura que se apresentam as microestruturas, denominadas de verbetes. Nas páginas finais da obra, geralmente são incluídos 
anexos, tabelas, bibliografia, informações enciclopédicas, etc. No entanto, esta disposição de elementos tende a variar de dicionário para dicionário, ficando a critério do autor ou organizador da obra incluir uma ou outra informação que julgar relevante para o consulente.

A microestrutura é composta por uma série de informações ordenadas dentro de cada verbete, constando dados dispostos de forma horizontal. Sobre o verbete, importa dizer que ele é a menor unidade autônoma do dicionário, sendo formado pelo lema, que é a palavra-entrada ${ }^{4}$, e por informações acerca dela. Desse modo, o verbete pode ser caracterizado como o conjunto das acepções e outras informações relacionadas à entrada do dicionário.

Quanto ao número de acepções, o verbete pode ser classificado como monossêmico, quando contempla apenas uma acepção, ou polissêmico, quando contempla duas ou mais. Acepção, por sua vez, define-se como cada um dos sentidos da palavra-entrada, aceito e reconhecido pelo uso, que no dicionário aparece verbalizado por uma definição lexicográfica.

Segundo Pontes (2009), fazem parte, essencialmente, de um verbete de dicionário escolar os seguintes paradigmas: palavra-entrada, categoria gramatical, definição. Outros elementos, tais como informações etimológicas, marcas lexicográficas, informações fônicas, exemplos e abonações de uso, fraseologias, subentradas, sinônimos e remissivas também podem aparecer, dependendo do tipo de dicionário, da feição da microestrutura e para quem a obra seja destinada.

Consequentemente, por conta da extensa gama de subsídios que oferece, é que Krieger (2003: 71) afirma com extraordinária precisão que "o dicionário é um lugar privilegiado de lições sobre a língua”. Entretanto, essa é uma obra que necessita ser melhor discutida, a fim de que possa se consolidar como um instrumento a ser mais explorado na escola.

\section{METODOLOGIA E ANÁLISE DAS MICROESTRUTURAS}

Nesta seção, apresentamos as análises contrastivas realizadas em microestruturas oriundas dos dicionários escolares Aurélio Júnior e Ruth Rocha, classificados como tipo 3, conforme referimos anteriormente. Devido às limitações deste trabalho, quais sejam um universo de mais de 60.000 verbetes, apresentamos apenas uma pequena amostra.

\footnotetext{
3 Vale destacar que pela visão da Lexicografia alemã a estrutura do dicionário costuma ser dividida em megaestrutura, nomenclatura, medioestrutura, material interposto e microestrutura.

${ }^{4} \mathrm{Ou}$ simplesmente entrada.
} 
Vale destacar que esta é a metodologia adotada ao se realizar análises e avaliações de dicionários, já que dada a extensão do corpus e a limitação de tempo e espaço é impossível investigar cada uma das microestruturas. Dessa forma, as análises são feitas por amostragem, considerando a seleção dos verbetes, cuja escolha se dá por meio de listas de verificação que incluem palavras de diversos campos temáticos, como: animais, frutas, esportes, profissões, homônimos etc.

Ressaltamos que a discussão dos aspectos microestruturais será feita sob a forma de análises isoladas. Optamos por esta metodologia, em função de considerá-la mais oportuna para a finalidade deste trabalho. Entretanto, algumas características não são exclusivas dos verbetes analisados, podendo ocorrer em outros, de maneira simultânea, visto que elas, por vezes, se interrelacionam.

Para a efetivação dos propósitos avaliativos, os verbetes foram transcritos de forma original, isto é, assim como estão dispostos nos dicionários. Após cada um deles, indicamos a obra com o título reduzido 5 . Posteriormente, fazemos breves análises metalexicográficas, nas quais apontamos características relativas às microestruturas das obras, conforme apresentamos a seguir.

\section{grampo}

gram.po subst. masc. 1. Peça de metal que segura e liga duas pedras, em uma construção. 2. Pedacinho de arame duro em forma de U, usado em grampeadores, para unir duas ou mais folhas de papel. 3. Gancho de metal para prender o cabelo feminino. (Aurélio Júnior).

gram.po sm 1 Peça de metal que prende e une duas pedras numa construção. 2 Peça para prender os cabelos. (Ruth Rocha).

Considerando os paradigmas básicos em cada uma das entradas lexicais, ambos os dicionários atendem aos princípios da Lexicografia. Embora atenda a tais princípios, o dicionário escolar tem uma maneira especial de elaboração, que começa com escolha de uma nomenclatura representativa do léxico usado nos textos escolares e nas disciplinas curriculares, passando pela elaboração de definições que utilizem um nível de linguagem adequado às necessidades e usos do consulente, neste caso, o estudante do ensino fundamental.

\footnotetext{
${ }^{5}$ A referência completa dos dicionários analisados pode ser conferida no final do texto.
} 
Observamos, em relação ao número de acepções, que o dicionário Aurélio Júnior contempla uma acepção a mais em relação à obra de Ruth Rocha. Notamos, ainda, que nos dois verbetes não há presença de exemplos, o que nos leva a crer que estas obras são mais voltadas para simples consultas relacionadas à significação das palavras do que para a produção textual. Entretanto, um dicionário indicado para o uso escolar deve contribuir também para a produção de textos, já que seus usuários estão em fase de aprendizagem da língua escrita. Dessa forma, os exemplos ajudam na compreensão do significado, como também mostram as formas como as palavras são empregadas no uso, constituindo-se em um auxílio a mais na aprendizagem.

Um outro aspecto que foi percebido refere-se à forma como é grafada a informação gramatical: o dicionário Aurélio Júnior prefere fazer uma abreviação maior (subst. masc.) que a do Minidicionário Ruth Rocha ( $\mathrm{sm}$ ). Entretanto, para saber o significado de todas as abreviações e símbolos utilizados nos dicionários, recomenda-se uma leitura prévia do prólogo e da lista de abreviações e símbolos, comumente dispostos na macroestrutura.

\section{rádio}

rá.di:o ${ }^{1}$ subst. masc. Ciências naturais. Osso longo que forma com o cúbito o esqueleto do antebraço. (Aurélio Júnior).

rá.di:o² subst. masc. Ciências naturais. Elemento químico, metálico, radioativo [Símbolo: $R a$ ]. (Aurélio Júnior).

rá.di:o ${ }^{3}$ subst. masc. 1. Radiofonia. 2. Aparelho ou conjunto dos aparelhos para emitir e transmitir sinais radiofônicos. 3. Aparelho receptor de programas radiofônicos. (Aurélio Júnior).

rá.di:o sm 1 (Quím.) Elemento de número atômico 88. Metal raro, prateado, que tem propriedades radioativas. É o sexto dos elementos na ordem de raridade. O nome vem de radius, "raio". Foi descoberto em 1898 por Pierre e Marie Curie. [Símb.: Ra.] 2 (Anat.) Osso que, com o cúbito, forma o antebraço. 3 Aparelho transmissor ou receptor de telefonia ou de telegrafia sem fio. Os primeiros aparelhos de rádio foram criados em 1898 por Guglielmo Marconi, físico italiano. (Ruth Rocha).

A maior característica que distingue as duas microestruturas é a forma como se organizam as entradas na macroestrutura em cada um dos dicionários analisados. Observamos nitidamente que o Aurélio Júnior se organiza macroestruturalmente considerando a homonímia; a palavra é pronunciada e escrita da mesma forma que outra, mas de origem e sentidos diferentes. Segundo Alpizar Castillo (1997: 124): 
[...] ao falar de homonímia se está, antes de tudo, diante de um eixo de diacronia; a homonímia tem sua explicação na evolução histórica das palavras [...] São exemplos: banco 'lugar onde se senta' (do alemão bank) / banco 'lugar onde se guarda dinheiro' (do italiano banca).

Ainda com relação a este modo de funcionamento da língua, Biderman (1998: 141) diz que:

Na moderna lexicografia, sobretudo aquela que se faz na França, o procedimento tem sido considerar homônimas palavras de grafia idêntica (mesmo significante) e significados muito distintos, a ponto de ser difícil para o falante identificar semas comuns aos dois ou mais homônimos. É o caso, por exemplo, de ponto, em que podemos identificar homônimos: ponto ${ }^{l}$ <porção do espaço designada com precisão> ponto ${ }^{2}$ <grau determinado numa escala de valores> $[\ldots]$.

O Minidicionário Ruth Rocha, por sua vez, opta por apenas uma entrada. Este critério em favor da polissemia está em um eixo sincrônico. Grosso modo, diz-se que uma mesma unidade léxica é polissêmica quando encerra vários significados. Sobre isso, Biderman (Ibidem: 141) ensina:

Hoje já não se discrimina os homônimos com base no mesmo étimo. Sendo possível identificar semas comuns, ou pelo menos um mesmo sema entre as várias acepções da palavra, ocorre polissemia; por conseguinte, o dicionarista deverá incluir esses valores semânticos como acepções da mesma lexia, num único verbete.

Vale destacar, ainda, que no verbete do Ruth Rocha figuram notas de caráter enciclopédico, muitas vezes confundidas com exemplos de uso. Essas notas, bem como os exemplos, podem auxiliar no processo de compreensão da unidade lexical, como também auxiliam o usuário na produção de textos, pois na nota a unidade lexical é empregada em um contexto de uso.

Outro aspecto que chama atenção é relativo à utilização de marcas lexicográficas ${ }^{6}$, que são paradigmas utilizados no dicionário para orientar e mostrar ao consulente as propriedades no uso das palavras e expressões. No caso dos verbetes em análise, observamos marcas de características diatécnicas ou tecnoletais ${ }^{7}$. Observemos que elas são diferentes nos dois dicionários: o Aurélio Júnior marca radio $^{1}$ e radio $^{2}$ como pertencente ao campo das Ciências Naturais, ao passo que o Minidicionário Ruth Rocha marca a primeira acepção como sendo pertencente à Química e a

\footnotetext{
${ }^{6}$ Este recurso é também denominado marca de uso ou rubrica.

${ }^{7}$ Um maior detalhamento acerca de marcas lexicográficas pode ser conferido em Pontes (2009).
} 
segunda acepção como sendo pertencente à Anatomia. Isso mostra que este tipo de informação, assim como muitos outros, pode variar de dicionário para dicionário.

\section{ilusionismo}

i.lu.si:o.nis.mo subst. masc. Prestidigitação. (Aurélio Júnior). i.lu.si:o.nis.mo $s m$ Prestidigitação. (Ruth Rocha).

\section{prestidigitação}

pres.ti.di.gi.ta.ção subst. fem. Arte e técnica de prestidigitador; mágica, ilusionismo. (Aurélio Júnior).

pres.ti.di.gi.ta.ção $s f$ Arte de prestidigitador; ilusionismo. (Ruth Rocha).

Neste caso, ocorre o que se pode chamar de definição circular ou circularidade. Observemos que foi necessário consultar outro verbete para se chegar à compreensão de que seja ilusionismo, motivo pelo qual trazemos à baila o verbete prestidigitação. As definições em ambos os dicionários não dão conta plenamente de descrever o sentido da palavra, visto que definem uma palavra por outra.

Ao adotar essa estratégia, isto é, a definição por sinônimo, o dicionário pode, geralmente, levar a uma circularidade, em que uma palavra $x$ é definida por $y$; em seguida $y$ é definida por $z$, que por sua vez é definido por $x$. Isto faz com que o usuário, apesar de consultar dois verbetes ou mais, muitas vezes se frustre por não encontrar o significado procurado ou, caso encontre, somente conseguirá depois de várias consultas.

Entretanto, a circularidade, que se sustenta por meio de uma rede de remissivas, quando bem estruturada, pode ser um grande complemento e um importante auxílio à consulta. Do contrário, as definições se consistirão apenas em "círculos viciosos", quando duas ou mais palavras se definem umas pelas outras sem que seja possível achar o significado de nenhuma.

Por fim, salientamos que no verbete do dicionário Aurélio Júnior, mesmo que organizado inadequadamente, tem-se ao menos uma pista do que prestidigitação pode significar, já que no 
contexto aparece a palavra mágica, fato que não acontece no verbete do Minidicionário Ruth Rocha.

\section{doninha}

do.ni.nha subst. fem. Zoologia. Mamífero mustelídeo. (Aurélio Júnior).

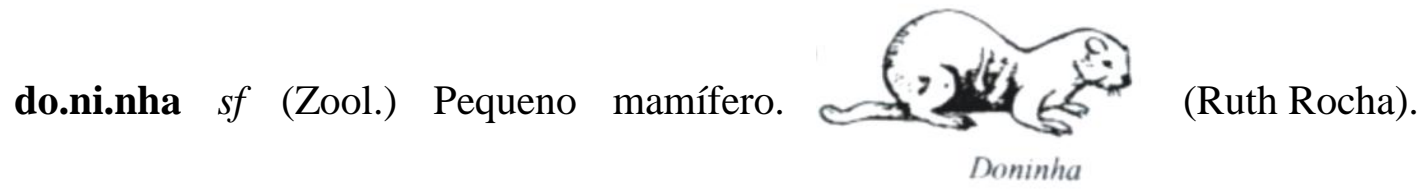

Aqui, percebemos, de início, uma diferença nítida: a presença de uma ilustração no verbete do Minidicionário Ruth Rocha. Nesta obra, muitos verbetes de animais acompanham ilustrações, no intuito, acreditamos, de auxiliar no entendimento do significado e de suprir possíveis lacunas deixadas pela definição. O dicionário Aurélio Júnior, por sua vez, não possui ilustrações.

Contudo, mesmo contando com um recurso poderoso como a ilustração, o usuário do Ruth Rocha acaba por não compreender o que de fato seja uma doninha, pois a definição, assim como acontece no verbete do Aurélio Júnior, é extremamente insuficiente. Aliado a isso, temos uma ilustração genérica, desprovida de detalhes, que não alcança o objetivo ao qual se propõe, que é o de ajudar o consulente a compreender o significado da unidade lexical.

Dessa forma, o consulente que consulta esses dicionários sabe apenas que doninha é um pequeno mamífero, mustelídeo, o que a rigor acaba por complicar ainda mais o entendimento da palavra, uma vez que existem diversos animais com as características definidas pelos dicionários: a lontra, o texugo e o furão, assim como a doninha, são pequenos, mamíferos e mustelídeos, entretanto, são animais diferentes.

Outro detalhe percebido foi que o dicionário Aurélio Júnior não utiliza abreviaturas nas marcas lexicográficas (neste caso, Zoologia), ao contrário do Ruth Rocha, que prefere utilizá-las no decorrer de toda obra. Neste contexto, cabe referir ainda que ambos os dicionários trazem listas de abreviaturas em suas macroestruturas. 


\section{morango}

mo.ran.go subst. masc. Infrutescência carnosa (e não o fruto) do morangueiro. (Aurélio Júnior). mo.ran.go sm Fruto do morangueiro. (Ruth Rocha).

O dicionário Aurélio Júnior utiliza no discurso definitório o termo infrutescência, que a nosso ver é bastante incomum para a idade dos usuários do dicionário, enquanto que o Minidicionário Ruth Rocha define a fruta apenas pelo óbvio. Apesar do Aurélio Júnior ainda dizer que morango não é um fruto, e sim uma infrutescência, entendemos ambas as microestruturas possuem excessiva generalidade e ampla vagueza na definição. Aliás, as definições das frutas nos dicionários geralmente se dão dessa forma: "mamão: fruto do mamoeiro; caju: fruto do cajueiro" etc.

\section{língua}

lín.gua subst. fem. 1. Ciências naturais. Órgão muscular, alongado, móvel, situado na cavidade bucal, e que serve para a degustação, a deglutição e a articulação dos sons da voz. 2. Objeto semelhante à língua (1). 3. O conjunto das palavras e expressões, faladas ou escritas, usadas por um povo ou uma nação, e o conjunto de regras de sua gramática. Bater ou dar com a língua nos dentes. Falar indiscretamente; revelar segredos. (Aurélio Júnior).

lín.gua $s f 1$ (Anat.) Órgão carnudo, móvel, situado na boca e que serve para degustar, para deglutir e para articular os sons. Dobrar a língua. loc. Falar com respeito. (Ruth Rocha).

Nessas microestruturas, observamos uma semelhança e algumas diferenças. Quanto à semelhança, podemos notar que os dois dicionários contemplam em seus verbetes expressões idiomáticas que contêm a palavra-entrada: bater ou dar com a língua nos dentes, no dicionário Aurélio Júnior, e dobrar a língua no dicionário Ruth Rocha, que opta por assinalar esse tipo de expressão como locução.

Vale dizer, é importante que um dicionário de natureza escolar traga em sua macro ou em sua microestrutura expressões como as que se apresentam, uma vez que mostram ao aluno possibilidades de uso da palavra-entrada, bem como auxiliam ao aluno a entender o significado de expressões que são utilizadas no dia a dia. Esta é uma ideia que defendemos, no entanto, a 
decisão de incluir expressões idiomáticas, locuções, fraseologias cabe ao(s) lexicógrafo(s) ou ao(s) organizador(es) de cada obra.

Sobre essas expressões, é necessário dizer que elas devem ser consideradas em sua plenitude, pois, se analisadas isolada ou literalmente, terão seus significados prejudicados, visto que possuem um sentido que não depende do somatório dos elementos constituintes da estrutura sintagmática. Assim, dobrar a língua não significa o ato de dobrar ou puxar o órgão carnudo, móvel, situado na boca, mas falar respeitosamente com alguém, como está definido em Ruth Rocha.

No plano das diferenças, percebemos uma que nos chamou bastante atenção, sobretudo, porque oculta uma acepção esperada em uma obra como um dicionário de língua portuguesa: não há no minidicionário Ruth Rocha uma acepção que considera língua como sistema, representação ou idioma constituído por palavras e por regras que as combinam em frases, visando à comunicação falada ou escrita. Tal significado é contemplado na acepção três do Aurélio Júnior.

Outro fato que percebemos foi que o dicionário Ruth Rocha coloca o número um antes da única definição que contempla no verbete, no sentido de marcar o número da acepção. Pode-se, no entanto, dispensar a numeração, pois a obra considera este verbete como monossêmico. A numeração de acepções é recomendada somente em verbetes polissêmicos, no intuito de separar as acepções para uma melhor compreensão do consulente, assim como acontece no Aurélio Júnior. Por fim, percebemos, assim como acontece no verbete rádio, que as duas obras utilizam marcas diatécnicas diferentes em suas microestruturas.

\section{CONSIDERAÇÕES FINAIS}

Reiteramos que o estudo apresentado neste artigo fundamenta-se na Lexicografia Pedagógica e na Metalexicografia, logo, não teve como finalidade eleger este ou aquele dicionário como melhor ou pior. Ao contrário, almejamos com estas breves análises críticocomparativas mostrar que o dicionário escolar pode ser passível de avaliação em relação à sua organização e elaboração, bem como auxiliar na compreensão de que tal obra é um valioso instrumento didático. 
Seria, portanto, um equívoco pensar que o dicionário se presta apenas para eventuais consultas de palavras, no intuito de revelar ao usuário significados imediatos e respostas prontas. Some-se a estes fatores

uma boa formação do professor de língua em Lexicografia Pedagógica, pois a ele cabem várias tarefas, entre elas, manusear todos os tipos de dicionários, compará-los criticamente assinalando as vantagens de uns e as insuficiências de outros, informar e guiar o aluno no oceano lexicográfico (Pontes \& Santiago, 2009: 105).

De tal modo, visamos de alguma maneira a contribuir com os estudos metalexicográficos, já que temos como filosofia a ideia de que os dicionários não são obras estagnadas (nem no tempo, nem no espaço), limitadas e acabadas tal qual a língua normatizada, ainda propagada por algumas gramáticas e professores. Visto dessa forma, os dicionários, em geral, são consideradas obras que servem apenas para serem consultadas e lidas. Em contrapartida, entendemos o dicionário, especialmente o utilizado em âmbito escolar, como um instrumento de atuação cultural, metalinguística e pedagógica, rico em potencialidades.

\section{REFERÊNCIAS}

Alpizar Castillo, R. (1997). ¿Cómo hacer un diccionario científico-técnico?. Buenos Aires: Memphis.

Biderman, M. T. C. (1998). Os dicionários na contemporaneidade: arquitetura, métodos e técnicas. In: Oliveira, A. M. P. P. \& Isquerdo, A. N (eds.) As ciências do léxico: lexicologia, lexicografia e terminologia. 129-142. v. I. Campo Grande: UFMS.

Krieger, M. G. (2006). Políticas públicas e dicionários para escola: o Programa Nacional do Livro Didático e seu impacto sobre a lexicografia didática. Cadernos de Tradução. XVIII (2), 235-252.

Krieger, M. G. (2004/2005). Dicionários para língua materna: princípios e critérios de escolha. Revista Língua e Literatura. 6/7 (10/11), 101-112.

Krieger, M. G. (2003). Dicionário de língua: um instrumento didático pouco explorado. In: Toldo, C. S. (ed.) Questões de linguística. 70-87. Passo Fundo: UPF Editora.

Pontes, A. L. (2009). Dicionário para uso escolar: o que é, como se lê. Fortaleza: EdUECE.

Pontes, A. L. \& Santiago, M. S. (2009). Crenças de professores sobre o papel do dicionário no ensino de Língua Portuguesa. In: Costa dos Santos, F. J. (ed.) Letras plurais: crenças $e$ 
metodologias do ensino de línguas. 105-123. Rio de Janeiro: CBJE. Disponível em: <http://projeto.unisinos.br/termilex>. Acesso: 12 mar. 2012.

\section{Dicionários analisados}

Ferreira, A. B. de H. (2005). Dicionário Aurélio Júnior: dicionário escolar da língua portuguesa. Curitiba: Positivo.

Rocha, R. (2005). Minidicionário da língua portuguesa/Ruth Rocha/Hindenburg da Silva Pires. São Paulo: Scipione.

\section{O AUTOR}

Márcio Sales Santiago é mestre em Linguística Aplicada pela Universidade do Vale do Rio dos Sinos (UNISINOS) e doutorando do Programa de Pós-Graduação em Letras (Estudos da Linguagem) da Universidade Federal do Rio Grande do Sul (UFRGS). Bolsista do CNPq.

E-mail: $\underline{\text { mssantiago12@gmail.com }}$ 